\title{
PROJETO DO CIRCUITO DE CAMPO DE UMA MÁQUINA DE INDUÇÃO TRIFÁSICA DIDÁTICA PARA FINS ACADÊMICOS
}

Leonardo Alves Fagundes Júnior - leonardo.fagundes@ufv.br

Augusto Cézar de Paula Araújo - augusto.paula@ufv.br

Caio Mauro Santana Cosme - caio.cosme@ufv.br

Mauro de Oliveira Prates-mauroprates@ufv.br

Universidade Federal de Viçosa - UFV, Departamento de Engenharia Elétrica - DEL Campus UFV

36570-900 - Viçosa-Minas Gerais

Resumo: Este trabalho trata das atividades desenvolvidas como parte da construção de uma máquina de indução trifásica (MIT) para fins didáticos. A fim de criar uma opção viável para as aulas na graduação, o projeto promete complementar e enriquecer o conhecimento prático em disciplinas que envolvam máquinas elétricas. Dessa forma, o MIT foi desenvolvido através de cálculos de parâmetros estruturais que nortearam o esboço em softwares para impressão 3D. O trabalho em questão apresenta as atividades desenvolvidas, que deram sequência ao projeto inicial, com ênfase nas técnicas utilizadas para realização do enrolamento de campo do MIT. O protótipo realizado foi submetido a testes práticos e comparado com seu modelo teórico. Resultados experimentais validam o método e o desenvolvimento propostos, observando-se os critérios de formação do campo girante.

Palavras-chave: Máquinas Elétricas. Enrolamento Estatórico. Campo Girante.

\section{INTRODUÇÃO}

Uma máquina elétrica é um dispositivo capaz de realizar uma conversão eletromecânica de energia (DEL TORO, 1994). O estudo da construção e do emprego das máquinas elétricas é essencial devido à grande quantidade de aplicações destas na indústria. Por isso, o aluno precisa estar a par dos conhecimentos necessários para atuar neste campo da engenharia, quando necessário. Por isso, o projeto de construção da máquina de indução trifásica (MIT) para fins didáticos está relacionado a uma facilitação do aprendizado da teoria aliado a uma modernização do ensino da disciplina, já que o desenvolvimento de toda a iniciativa conta com elementos teóricos e tecnologias de simulação, além de impressão 3D.

Na máquina de indução, como em um transformador, a corrente é fornecida para o rotor através da indução por meio da alimentação de corrente alternada diretamente ao estator. Desse modo, um campo magnético girante é produzido para a excitação da máquina e sua velocidade é determinada pela quantidade de polos e pela frequência aplicados ao estator (DEL TORO, 1994; SEN, 2007).

Duas expressões comumente usadas para descrever os enrolamentos de uma máquina são enrolamentos de campo e enrolamentos de armadura. Em geral, a primeira expressão é aplicada aos enrolamentos que produzem o campo magnético principal da máquina, e, a seguinte, relacionada aos enrolamentos nos quais é induzida a tensão principal (CHAPMAN, 2013). Umans e Laschuk, (2014), definem que um grupo de bobinas, conectadas em conjunto, é referido normalmente como enrolamento de armadura. Sendo assim, o termo enrolamento 
de armadura de uma máquina rotativa se refere a um enrolamento ou grupo de enrolamentos que conduzam corrente alternada.

O projeto atual, que trata da construção do modelo didático de uma máquina de indução trifásica, se iniciou com a análise da estrutura de motores semelhantes no laboratório de máquinas elétricas da UFV. A partir do modelo proposto, foram realizadas pesquisas, principalmente desenvolvidas por (MARTIGNONI, 1978), para determinação dos parâmetros da máquina, tanto físicos quanto elétricos, a fim de construí-la, com o menor custo e maior eficiência possíveis, a partir das ferramentas passíveis de desenvolvimento em impressoras 3D (GOUVEA et al., 2019).

A partir das pesquisas anteriores e com base no modelo de motor de indução presente no laboratório, foi definido que o modelo a ser projetado seria do tipo rotor em gaiola de esquilo, por ser um dos mais utilizados dentro desta classe de máquinas (UMANS e LASCHUK, 2014). Com algumas partes do MIT (estator, rotor e tampas dianteira e traseira) impressas, foi necessário realizar o enrolamento de campo da máquina, com dois polos, de modo que as espiras de fases diferentes estejam separadas entre si de 120 graus elétricos (GUEDES, 1993).

Este trabalho é uma continuação do projeto de pesquisa iniciado por (GOUVEA et al., 2019) e tem como objetivo o desenvolvimento de máquinas de indução trifásicas, baseadas nos princípios estudados nas disciplinas de máquinas elétricas, para serem aplicadas como equipamentos didáticos em disciplinas do curso de Engenharia Elétrica. Para isso, desenvolve-se aqui a análise acerca da construção do circuito de campo da máquina.

\section{MATERIAL E MÉTODOS}

\subsection{Projeto da máquina}

O dimensionamento das partes da máquina impressa, assim como os resultados de desempenho esperados foram feitos por meio dos cálculos e tabelas desenvolvidos por (MARTIGNONI, 1978) e explicados (GOUVEA et al., 2019). Assim, foram obtidos os parâmetros de acordo com a Tabela 1:

Tabela 1 - Parâmetros construtivos da máquina.

\begin{tabular}{|l|c|}
\hline \multicolumn{1}{|c|}{ Parâmetros } & \\
\hline Número de ranhuras do estator & 18 \\
\hline Número de ranhuras do rotor & 24 \\
\hline Canais por polo e por fase no estator & 3 \\
\hline Número de condutores por fase no rotor & $5,4 \mathrm{~cm}$ \\
\hline Diâmetro do rotor & $7,66 \mathrm{~cm}$ \\
\hline Comprimento geométrico do estator & 78 \\
\hline Condutores por canal por fase & \\
\hline
\end{tabular}

Fonte: (GOUVEA et al., 2019).

\subsection{Enrolamento de Campo}

A Figura 1 apresenta um diagrama do enrolamento do estator feito, visto de sua superfície interna, mostrando como as correntes produzem os polos magnéticos $\mathrm{N}$ (norte) e $\mathrm{S}$ (sul). Neste caso, B é a densidade de fluxo resultante. Os pontos e cruzes indicam fluxos de corrente que se aproximam ou se afastam do leitor, respectivamente.

O circuito elétrico estatórico é formado por um enrolamento com três bobinas afastadas no espaço de $2 \pi / 3$ radianos elétricos, e destinadas a serem alimentadas por cada uma das fases de um sistema trifásico (NASCIMENTO, 2011). O enrolamento do circuito de estator 


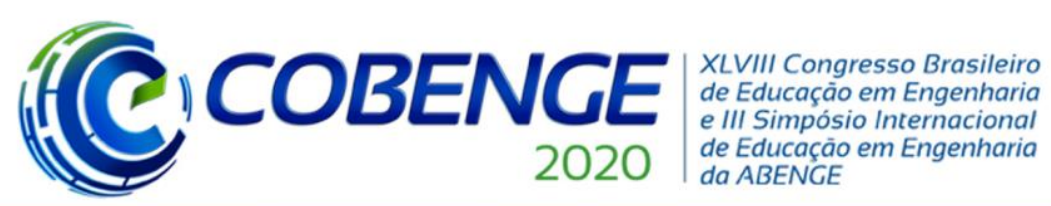

"Os desafios para formar hoje o engenheiro do amanhã"
$\mathrm{Ol}$ a $\mathrm{O} 3$ de dezembro Evento On-line

projetado conta com 5 bobinas em cada fase, de modo que cada bobina contém 23 espiras, ou seja, cada fase tem 115 voltas.

Figura 1 - Diagrama do enrolamento do estator.

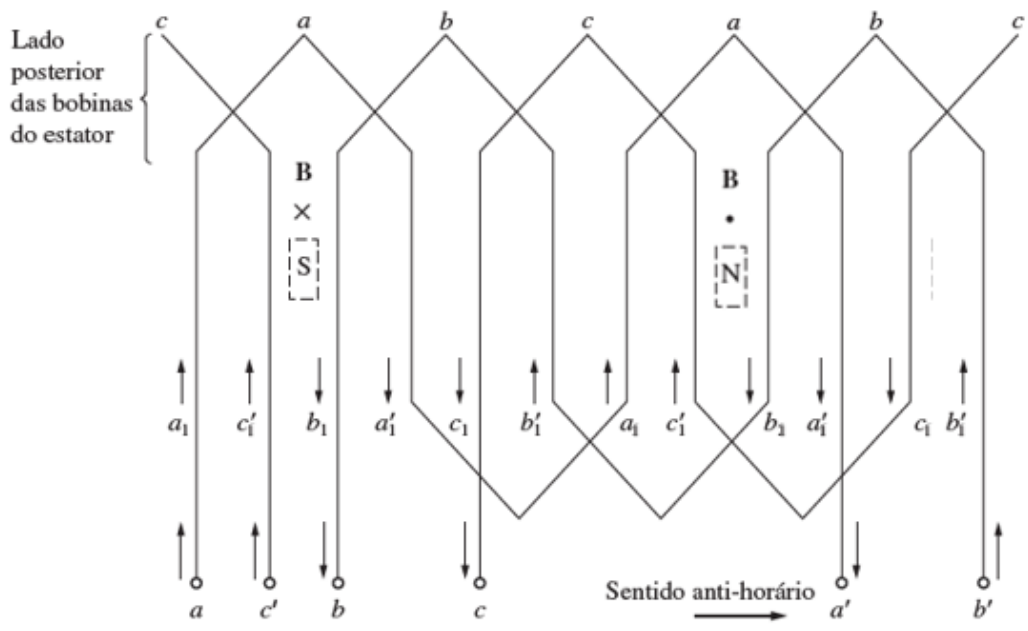

Fonte: Adaptado de (CHAPMAN, 2013)

O estator desenvolvido tem 18 ranhuras, sendo este de dois polos, de modo que haja 3 ranhuras por polo e por fase, como apresentado no esquema da Figura 2.

Figura 2 - Estator do MIT projetado: (a) peça impressa; (b) Esquemático.

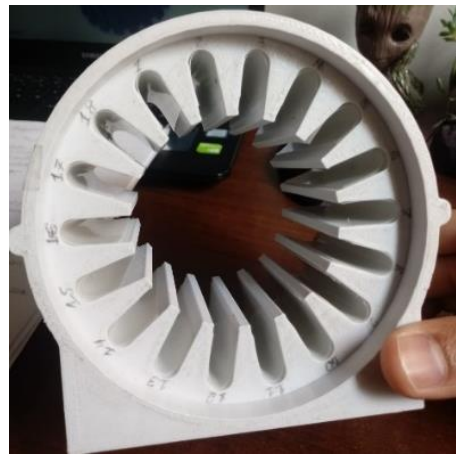

(a)

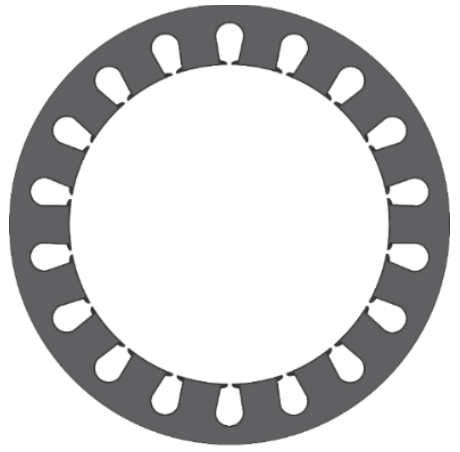

(b)

Fonte: Autores.

Seguindo o enrolamento proposto na Figura 1, o primeiro passo foi realizar o circuito da fase $A$. Enumerando-se as ranhuras da carcaça, o desenvolvimento consistiu em separar as fases de 120 graus elétricos entre si, neste caso, o passo geométrico referente é de 6 ranhuras. Ou seja, quando passado o condutor de uma fase em uma determinada ranhura, o respectivo condutor de outra fase deverá estar localizado a 6 ranhuras, no sentido horário, deste primeiro.

O início do enrolamento está na ranhura 1, "entrando na folha". O resultado é apresentado na Figura 3(a), explicitando as $i$-bobinas, com $i=1, \ldots, 5$. Nessa e nas imagens seguintes as cruzes e os pontos indicam condutores que entram ou saem da determinada ranhura, respectivamente. Com "entrar" e "sair" da ranhura dizemos que o sentido de enrolamento é único, a saber, sentido anti-horário, como na Figura 1. Cada fase é composta por cinco bobinas, com 23 condutores cada uma. 


\section{COBENGE CCOBENCE: 2020 da ABENGE}

\section{"Os desafios para formar hoje o engenheiro do amanhã"}

Figura 3 - Representação do enrolamento estatórico da fase: (a) $\boldsymbol{A}$, (b) $\boldsymbol{B}$ e (c) $\boldsymbol{C}$.

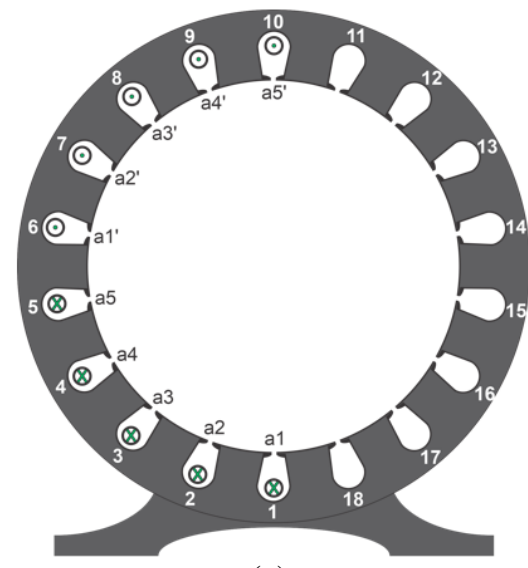

(a)

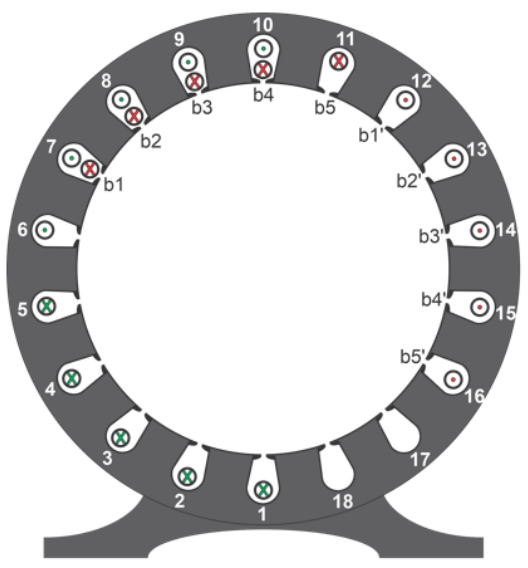

(b)

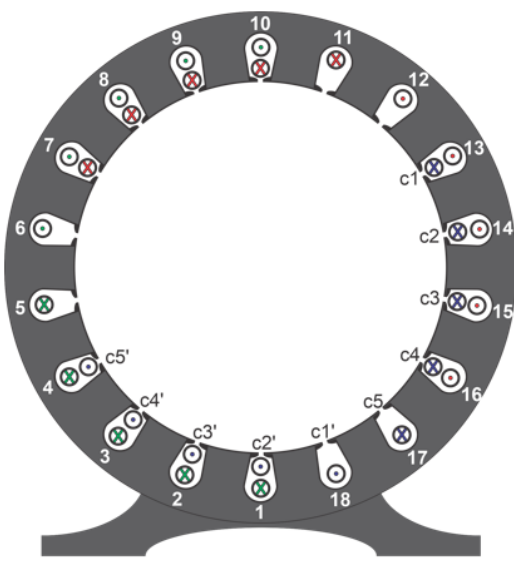

(c)

Fonte: Autores.

A bobina 1 é encaixada nas ranhuras 1 e 6 , sendo seu início em 1 e seu final em 6 . A próxima bobina é continuação da primeira. Então, o fim da bobina 1 entra na ranhura 2, início da segunda bobina, representada pelos índices $a 2$ e $a 2^{\prime}$, e assim sucessivamente até a última bobina. Neste contexto, o início da fase $A$ está na ranhura $1(a 1)$ e seu final, na ranhura 10 $\left(a 5^{\prime}\right)$, o primeiro "entrando", e o segundo, "saindo da tela".

A mesma metodologia foi adotada na sequência para o enrolamento das fases $B$ e $C$. A Figura 3(b) e (c) apresenta a estratégia de enrolamento. Neste caso, a fase $B$ começa na ranhura 7, com um passo de 6 a partir da ranhura 1, e termina em 16. Analogamente, a fase $C$ inicia-se na ranhura 13, e termina na ranhura 4. Com isso, o circuito estatórico resultante é da forma apresentada na Figura 4(a). Os condutores elétricos isolados a esmalte, que formam as diversas espiras das bobinas, estão dispostos a duas camadas na ranhura, e encontram-se isolados do material do estator por um material isolante plástico, que forra a parte inferior da ranhura. Além disso, estão travados na ranhura por regletes plásticas. Neste projeto, utilizouse fios AWG de 0,5 mm. O estator enrolado é apresentado na Figura 4(b).

Figura 4 - (a) Esquemático do enrolamento de campo do MIT, (b) Estator com enrolamento de campo.

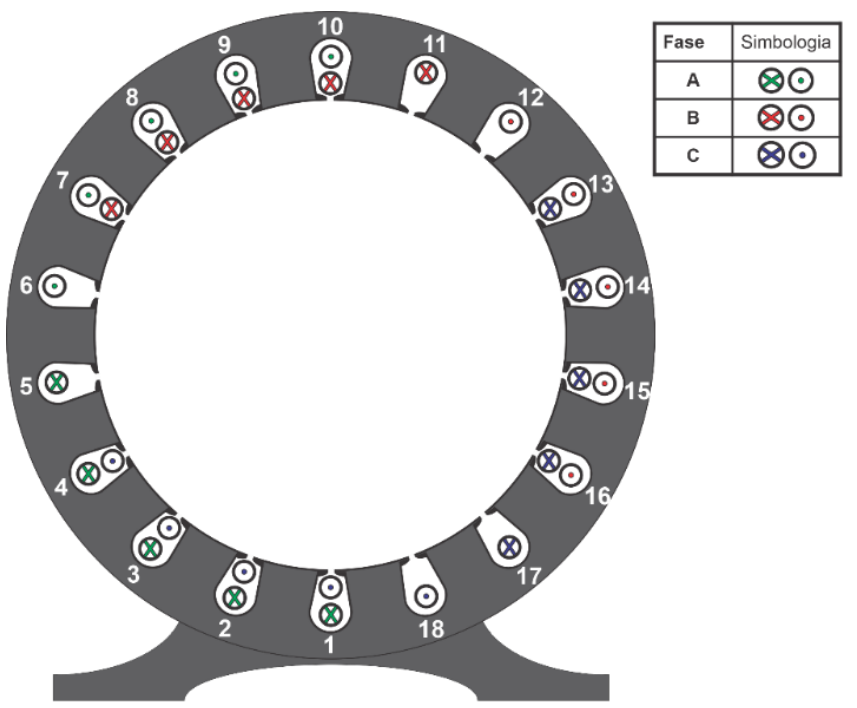

(a)

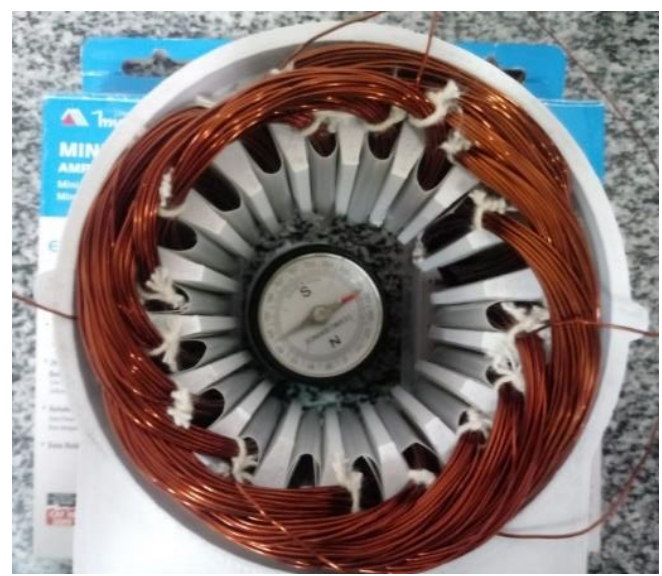

(b)

Fonte: Autores. 


\subsection{Teste de Polaridade}

Um dos testes necessários antes da ligação da máquina CA é a garantia que os seus enrolamentos de campo terão todos a mesma polaridade de ligação, onde os pares de entrada e saída serão ligados em terminais opostos de alimentação. A forma utilizada para determinação de polaridade das espiras foi utilizando uma bateria de $9 \mathrm{~V}$ e um voltímetro analógico de tensão contínua, como mostra a Figura 5.

Figura 5 - Circuito para teste de polaridade das espiras.

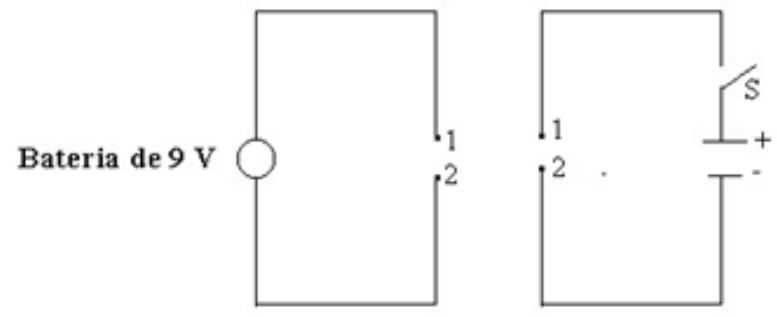

Fonte: Autores.

O procedimento ocorre da seguinte maneira:

1. O terminal positivo da bateria é ligado a um dos terminais do enrolamento, convencionalmente aqui chamado de 1, enquanto o negativo será ligado ao outro terminal, chamado então de 2 . O terminal 1 será o início e o 2 o fim do enrolamento. Ao se conectar o voltímetro nos mesmos terminais e da mesma forma, pode-se analisar a deflexão de seu ponteiro: caso seja positiva, confirma-se o terminal 1 como início e 2 como final.

2. A bateria é mantida no primeiro enrolamento e o voltímetro é mudado para o seguinte, observando a deflexão quando ligada ao outro enrolamento: caso a deflexão seja positiva o terminal ligado ao polo positivo será o final do enrolamento, se for negativa, será o início do enrolamento.

\subsection{Teste de Campo Girante}

Segundo Chapman, (2013), o princípio fundamental do funcionamento das máquinas CA é que, se correntes trifásicas, todas de mesma intensidade e defasadas de $120^{\circ}$ entre si, estiverem fluindo em um enrolamento trifásico, um campo magnético girante de intensidade constante será produzido (WEG, 2012).

A Figura 6 mostra que o campo magnético girante do estator pode ser representado como um polo norte (onde o fluxo deixa o estator) e um polo sul (onde o fluxo entra no estator). Esses polos magnéticos dão uma volta mecânica completa ao redor do estator para cada ciclo elétrico da corrente aplicada. Portanto, a velocidade mecânica de rotação do campo magnético, em rotações por segundo, é igual à frequência elétrica em Hz. $B_{s}$ é usado para o campo magnético do estator e $\omega_{s m}$ representa a velocidade mecânica dos campos magnéticos do estator em radianos por segundo (DE OLIVEIRA, 2009). O campo magnético girante, produzido no estator, gira na velocidade síncrona, e esta velocidade depende apenas da frequência da tensão aplicada ao estator, e do número de polos da máquina (GUEDES, 1993; NASCIMENTO, 2011). O número de rotações do campo magnético girante pode ser calculado através da equação (1).

$$
n_{s m}=120 \frac{f_{s e}}{P}
$$


(C) COBENGE 2020

"Os desafios para formar hoje o engenheiro do amanhã"
$\mathrm{O}$ a $\mathrm{O3}$ de dezembro Evento On-line

onde $n_{s m}$ é dada em rotações por minuto $(\mathrm{RPM}), f_{s e}$ é a frequência elétrica $(\mathrm{Hz})$ e $P$, o número de polos da máquina (CHAPMAN, 2013; SEN et al., 2007). Neste caso, para aplicação no sistema trifásico a $60 \mathrm{~Hz}$, a velocidade do campo girante é de 3600 RPM.

Figura 6 - O campo magnético girante em um estator, representado como polos norte e sul girando no estator.

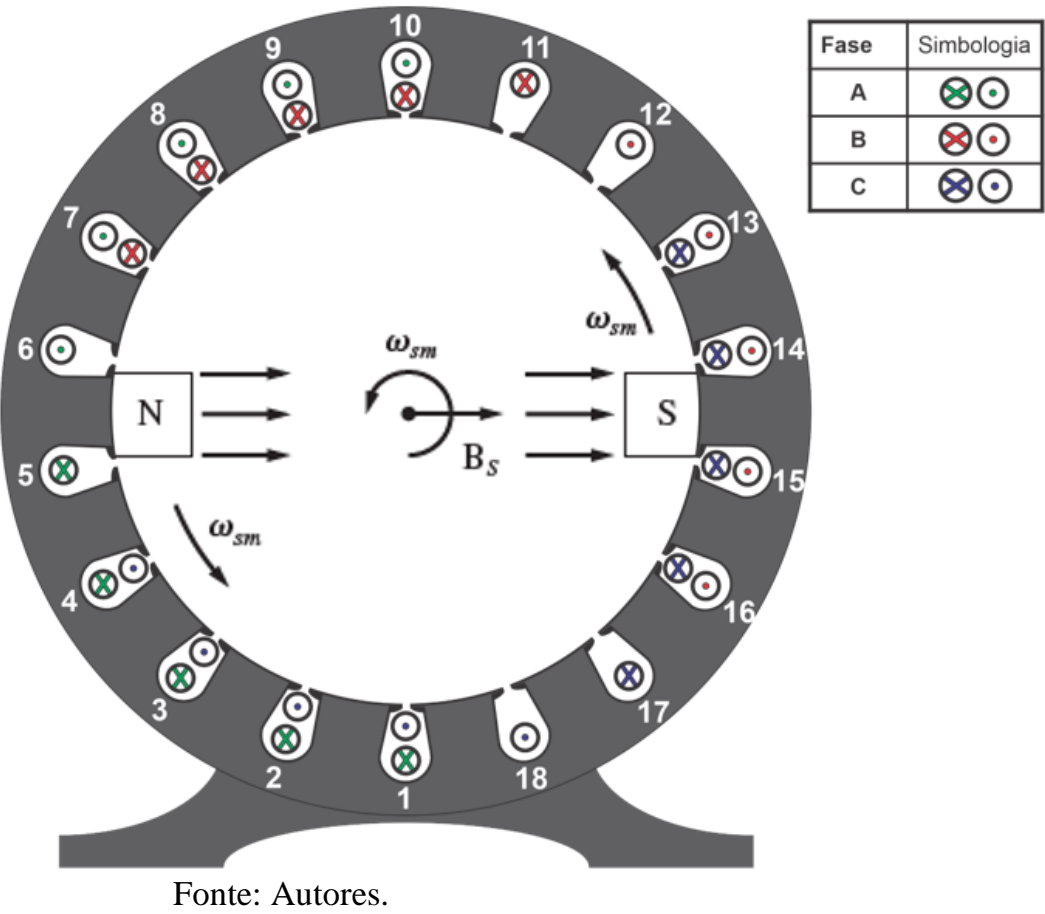

Para verificar a formação do campo girante foram realizados ensaios com o estator ligado em estrela alimentados por uma fonte de tensão CA variável (ou varivolt), e, utilizando-se uma bússola no centro do estator, varia-se a tensão para observação do campo girante.

Os ensaios foram realizados de acordo com o esquema de ligação mostrado na Figura 7.

Figura 7 - Circuito montado para o ensaio a vazio do estator.

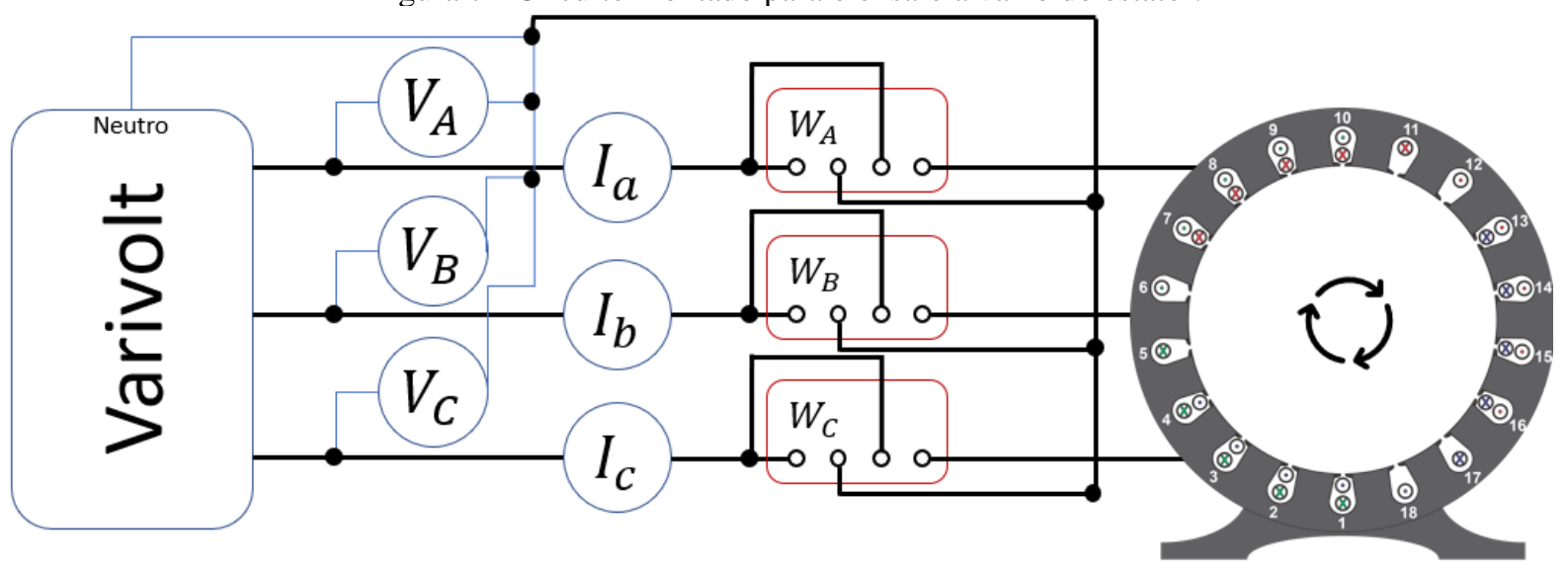

Fonte: Autores. 


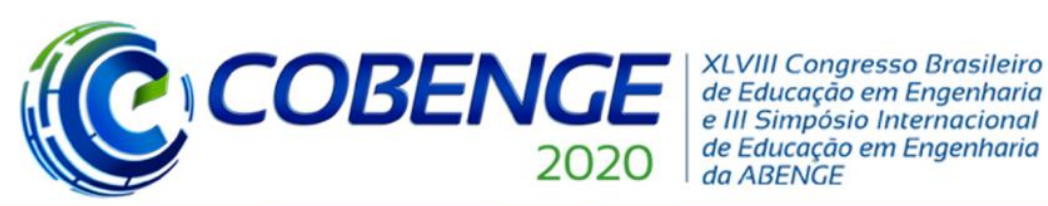

"Os desafios para formar hoje o engenheiro do amanhã"

\subsection{Projeto de Estator/ Casca e Tampas Propostos}

O projeto inicialmente proposto foi o apresentado na Figura 8 (GOUVEA et al., 2019).

Figura 8 - Primeiro protótipo: (a) estator; (b) tampa.

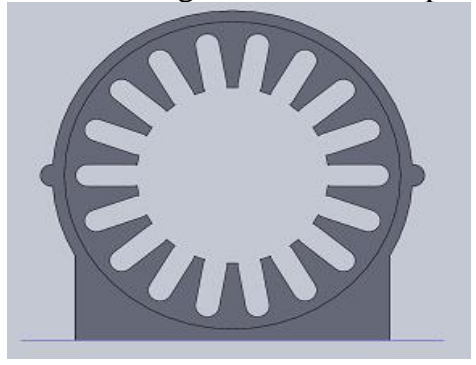

(a)

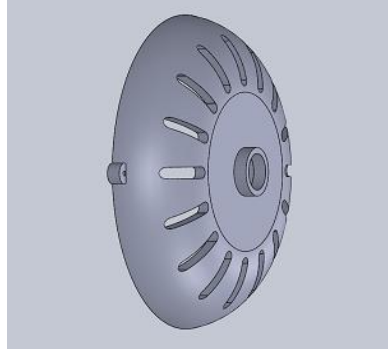

(b)

Fonte: (GOUVEA et al., 2019).

O estator do motor de indução trifásico é constituído por um empacotamento de chapa de ferro magnético silicioso, com baixa densidade de perdas magnéticas que forma o circuito magnético estatórico. As chapas têm uma forma de coroa circular ranhurada na periferia interior; estão revestidas de um verniz isolante. As ranhuras são semifechadas, e destinam-se a conter os condutores do circuito eléctrico estatórico (GUEDES, 1993; CORREIA, 2014). Entre conjuntos de chapas magnéticas podem existir canais de ventilação, que servirão para a passagem do ar de refrigeração. Como propostas de melhoria, foram projetadas as peças mostradas na Figura 9.

Figura 9 - Novas propostas da casca do motor.

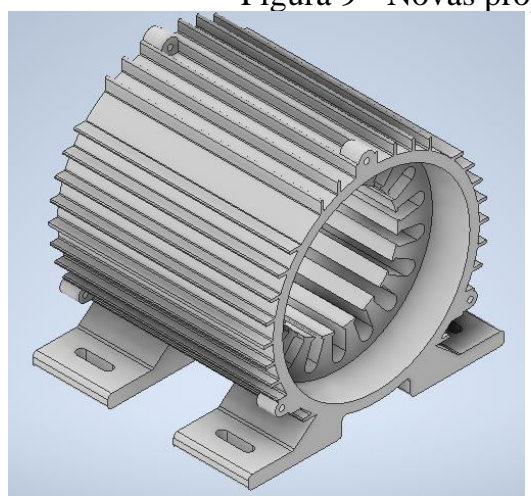

(a)

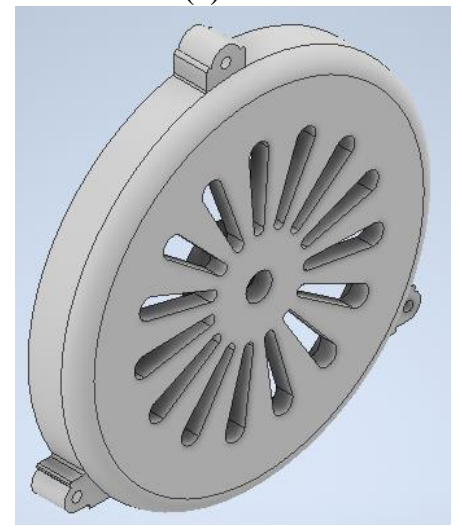

(c)

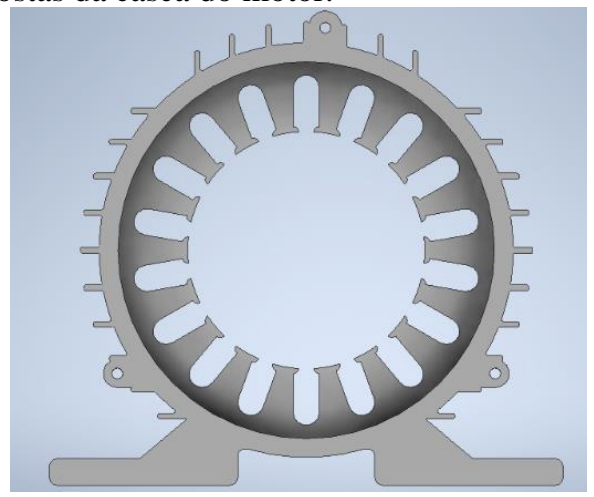

(b)

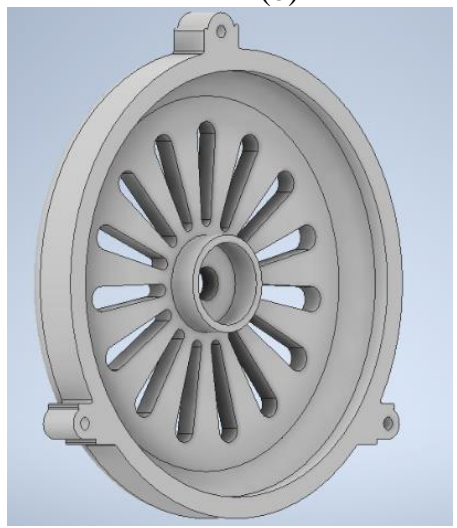

(d)

Fonte: Autores. 


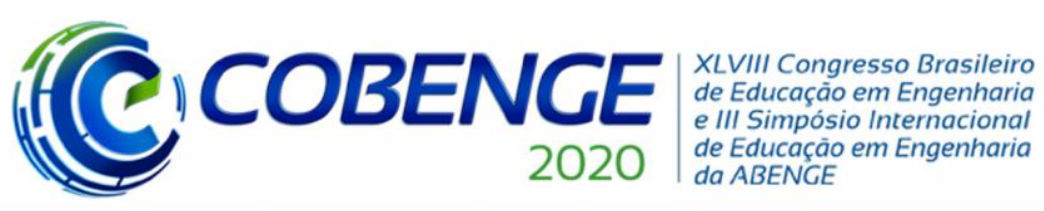

"Os desafios para formar hoje o engenheiro do amanhã"

\section{RESULTADOS E DISCUSSÕES}

\subsection{Testes de Polaridade e de Campo Girante}

Através do teste de polaridade observou-se que o início e o fim das bobinas de cada fase coincidiram com o projeto inicial de enrolamento, apresentado por (GOUVEA et al., 2019). O que corrobora com os resultados positivos do funcionamento do campo.

\subsection{Enrolamento de Campo}

Para verificar a formação do campo girante foram realizados ensaios com o estator ligado em estrela em um varivolt. Uma bússola é inserida no centro do estator. Variando-se a tensão em níveis em torno de $0,1 \mathrm{~V}$ traçou-se curvas a partir da coleta de dados e da observação da intensidade do campo girante sobre a bússola. Verifica-se que o campo girante é gerado uma vez que a bússola começa a girar com determinada velocidade. $\mathrm{O}$ aumento da tensão nos terminais de entrada do estator, e consequentemente aumento da corrente estatórica, implica em elevação do módulo da intensidade de campo, que é diretamente proporcional a corrente que circula no condutor. Dado isso, a velocidade de rotação da bússola deve aumentar com o aumento da intensidade do campo girante.

Nos ensaios produzidos do campo girante, foram constatados os valores de tensão e corrente, de acordo com as variações descritas anteriormente. Assim, foram feitos tais testes com a máquina "fria" e com a máquina "quente", depois das sucessivas variações. Pode-se notar na Figura 10 que as fases $\mathrm{A}$ e $\mathrm{C}$ apresentam comportamentos praticamente iguais, enquanto a curva da fase B apresenta um comportamento diferente. Isso pode gerar problemas no campo girante que não puderam ser detectados agora, impossibilitando o giro do rotor.

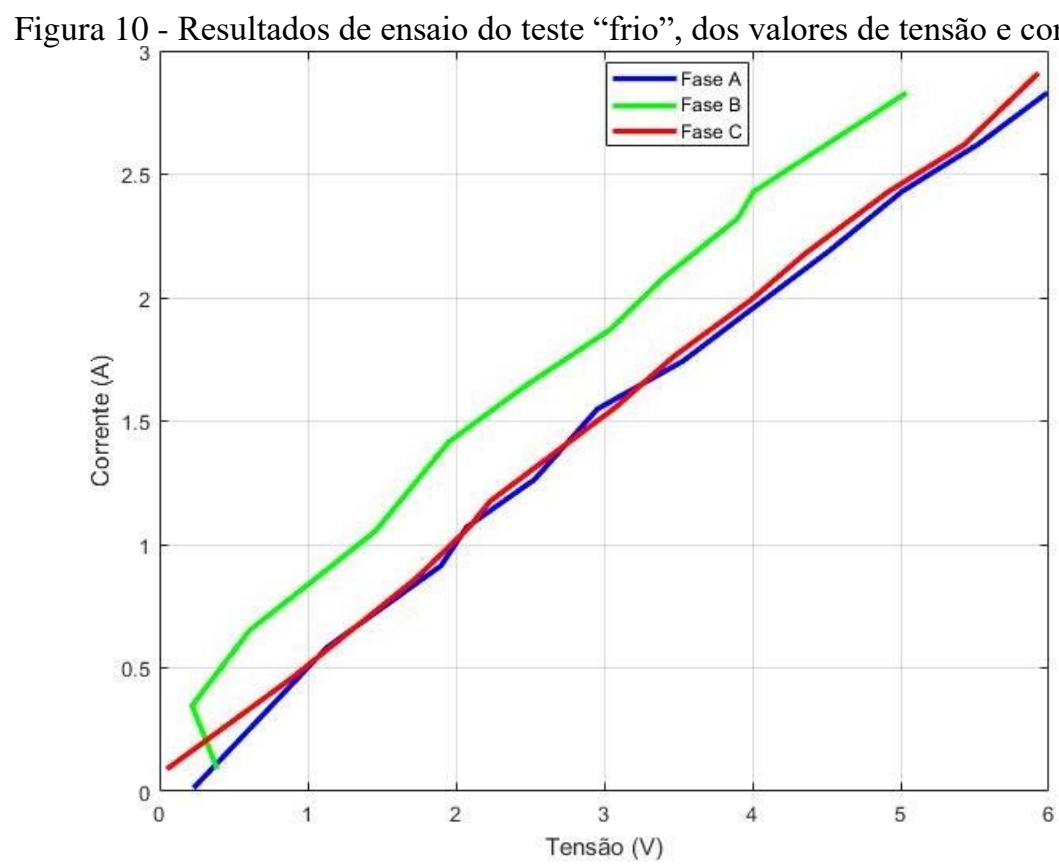

Fonte: Autores.

Com os ensaios do motor "quente", os resultados do ensaio foram semelhantes, portanto seus gráficos foram omitidos.

Também foram medidas as resistências efetivas de cada fase do estator, que geraram um valor médio de $1,9 \Omega$, o que pode ajudar a calcular as perdas de potência totais, após o funcionamento da máquina. 


\section{CONSIDERAÇÕES FINAIS}

Através do trabalho de construção da MIT em impressora 3D foi possível, através de extensa pesquisa bibliográfica, encontrar um método adequado para o enrolamento estatórico. Dessa forma, através de sucessivas tentativas e cuidados com isolamento entre as fases, acoplamento ideal ao estator e diminuição máxima das folgas nas bobinas, foi alcançado sucesso em gerar um bobinamento adequado para um campo girante e, assim, feitos testes a fim de se determinar alguns parâmetros e traçar curvas necessárias do motor. Através dos resultados obtidos dos ensaios é possível notar que se deseja um comportamento mais uniforme das três fases, para evitar problemas de funcionamento na máquina.

Além disso, a fim de otimizar os resultados alcançados, deve-se aumentar o número de espiras por fase, o que ocasiona em um maior fluxo girante para o rotor. Assim, para os próximos passos, além de completar o enrolamento com mais espiras, deseja-se terminar o curto-circuito das ligações do rotor e entre seus anéis, usinar o eixo no rotor, para fazê-lo rodar e conectar as partes com a tampa, o que proporciona condições ideais para que o MIT funcione como a máquina desejada inicialmente.

\section{Agradecimentos}

Ao apoio do CNPq/PIBIC com a concessão de bolsa de iniciação científica, ao departamento de Engenharia Elétrica da UFV e pelo auxílio prestado no desenvolvimento do projeto.

\section{REFERÊNCIAS}

CHAPMAN, Stephen J. Fundamentos de máquinas elétricas. $1^{\text {a }}$ edição, Porto Alegre: AMGH Editora, 2013.

CORREIA, Adalberto Junqueira Livramento. Estimação de Parâmetros Mecânicos de Motores de Indução Trifásicos com Rotor em Gaiola de Esquilo. 2014. 145 f. Dissertação (Mestrado). Instituto Superior de Engenharia de Coimbra, Coimbra, 2014.

DE OLIVEIRA, João Gabriel Souza Martins. Materiais usados na construção de motores elétricos. Pontifícia Universidade Católica do Rio Grande do Sul. Seminário Técnico, PUCRS, Rio Grande do Sul, 2009.

DEL TORO, Vincent. Fundamentos de máquinas elétricas. $1^{a}$ edição, : Prentice-Hall do Brasil, 1994.

GOUVEA, Rodrigo A.; RIBEIRO, Brisa P.; FAGUNDES, Leonardo A. Jr.; DE PAULA, Augusto C. A.; PRATES, Mauro de O. PROJETO DE UMA MÁQUINA DE INDUÇÃO TRIFÁSICA DIDÁTICA PARA FINS ACADÊMICOS. In: XLVI Congresso Brasileiro de Educação em Engenharia, 2019, Ceará. Anais COBENGE 2019 - ISSN 2175 - 957X.

Fortaleza, 2019.

GUEDES, Manuel Vaz. O Motor de Indução Trifásico: modelização. Faculdade de Engenharia. Universidade do Porto, Porto, 1993. 
"Os desafios para formar hoje o engenheiro do amanhã"

MARTIGNONI, Alfonso. Máquinas de Corrente Alternada. $3^{\text {a }}$ edição, Porto Alegre: Editora GLOBO, 1978.

NASCIMENTO, Geraldo Carvalho. Máquinas Elétricas: Teoria e Ensaios. $4^{\mathrm{a}}$ edição, São Paulo: Editora Érica, 2011.

SEN, Paresh Chandra. Principles of electric machines and power electronics. John Wiley \& Sons, 2007.

UMANS, Stephen D.; LASCHUK, Anatolio. Máquinas Elétricas De Fitzgerald E Kingsley. $7^{\text {a }}$ edição, Porto Alegre: Editora AMGH. 2014.

WEG, S. A. Motores elétricos: Guia de especificação. WEG, Jaraguá do Sul-SC, 2012.

\title{
FIELD CIRCUIT DESIGN OF A THREE-PHASE INDUCTION MACHINE FOR ACADEMIC PURPOSES
}

\begin{abstract}
This work deals with the activities developed as part of the construction of a threephase induction machine (MIT) for didactic purposes. In order to create a viable option for undergraduate classes, the project promises to complement and enrich practical knowledge in disciplines involving electrical machinery. Thus, the MIT was developed through calculations of structural parameters that guided the sketch in $3 D$ printing software. The work in question presents the activities developed, which followed on from the initial project, with emphasis on the techniques used to carry out the MIT field winding. The prototype was submitted to practical tests and compared with its theoretical model. Experimental results validate the proposed method and development, observing the formation criteria of the rotating field.
\end{abstract}

Keywords: Electrical Machines, State winding, Rotating Field. 